\title{
Study on the Mixed Materials Proportion of Stratum Based on the Modelling Experiment
}

\author{
Yijun Zhou' ${ }^{1}$ and Tao Xu ${ }^{2}{ }^{2}$ \\ ${ }^{1}$ College of Architecture and Engineering, North China University of Science and Technology, Tangshan 063210, China \\ ${ }^{2}$ School of Civil Engineering, Southeast University, Nanjing 211189, China \\ Correspondence should be addressed to Tao Xu; xu-tao@seu.edu.cn
}

Received 4 May 2021; Accepted 19 May 2021; Published 26 May 2021

Academic Editor: Xiaohu Zhang

Copyright $\odot 2021$ Yijun Zhou and Tao Xu. This is an open access article distributed under the Creative Commons Attribution License, which permits unrestricted use, distribution, and reproduction in any medium, provided the original work is properly cited.

\begin{abstract}
It is highly significant to select similar materials as well as the proportion of mixed materials in the model test. The mixed materials are used to simulate the stratum of the model test, including the iron ore powder, natural sands, gypsum, and lime. The stratum contains silty clay and silt soil. First of all, the symmetry coefficient of model mechanics parameters are calculated by the equation, and the symmetry ratio is $16: 1$. Second, calculate the proportion of compositions in mixed materials by the orthogonal test. The deviation method is used to analyze the mixed materials and how to influence the elastic modulus, cohesion, and friction angle. Finally, get the mixed materials which meet the symmetry theory and control factors.
\end{abstract}

\section{Introduction}

The model test is a method that uses the symmetry theory to reduce the size of the prototype. The symmetrical material is highly significant to the model test, and it usually contains some kinds of materials called mixed materials. Choosing suitable mixed materials can determine the model test whether success or not [1-3].

The mixed materials have been researched by some researchers. In abroad, Fumagalli [4] researched the model test of engineering geology initially in the 1960s. He used gypsum, powder of $\mathrm{PbO}$, expansive soil, and water to simulate the stratum. Han et al. [5] researched the materials of MIB to study the rock and soil. Wang [6] selected the barite, quartz, and vaseline to study proportion of mixed materials in the model test. He found that different proportions of mixed materials lead to different results of the test. Chen and Zuo $[7,8]$ introduced several materials to study the influence for proportion of stratum, including $\mathrm{PbO}$, gypsum, expansive soil, sands, starch, hardener, and so on.

The symmetry theory is mainly used to guide the model test to determine the proportion for the model and prototype [9-12].
The geology model test is highly complex and is affected by lots of factors, such as density of soil, cohesion of soil, friction angle of soil, elastic modulus of soil, and so on. Therefore, the much more important factor must be controlled, ignoring the less important factors [13-17].

To measure the proportion of mixed materials, some kinds of methods are introduced, including the direct shear test, orthogonal test, deviation analysis method, three axes test, and so on [18-26].

\section{Materials and Methods}

\subsection{Determination of Symmetry Coefficient of Stratum}

2.1.1. Symmetry Ratio. In the process of the model test, the symmetry ratio is a crucial step and also determines the model test whether it can correctly react to objective laws or not. The symmetry ratio is the ratio between the prototype and the model and marked $C$. The definitions of model test parameters are as follows: $L$ is the length, $r$ is the density, $\delta$ is the displacement, $\sigma$ is the stress, $\varepsilon$ is the strain, $\sigma^{t}$ is the tensile strength, $\sigma^{c}$ is the compressive strength, $c$ is the cohesion, $\phi$ is the friction angle, $\mu$ is Poisson's ratio, and $f$ is 
the coefficient of friction. All of the parameters of symmetry ratio are given in Table 1.

2.1.2. Establishment of Symmetry Equation. According to the symmetry theory, establish the equation of the prototype and model, including the equilibrium equation, geometric equation, and physical equation.

(1) Establish a symmetrical condition by the equilibrium equation:

$$
\begin{array}{|l}
\text { Equilibrium equation of prototype: }\left\{\begin{array}{l}
\left(\frac{\partial \sigma_{x}}{\partial x}\right)_{p}+\left(\frac{\partial \tau_{y x}}{\partial y}\right)_{p}+\left(\frac{\partial \tau_{z x}}{\partial z}\right)_{p}+X_{P}=0 \\
\left(\frac{\partial \sigma_{y}}{\partial y}\right)_{p}+\left(\frac{\partial \tau_{z y}}{\partial z}\right)_{p}+\left(\frac{\partial \tau_{x y}}{\partial x}\right)_{p}+Y_{P}=0 \\
\left(\frac{\partial \sigma_{z}}{\partial z}\right)_{p}+\left(\frac{\partial \tau_{x z}}{\partial x}\right)_{p}+\left(\frac{\partial \tau_{y z}}{\partial y}\right)_{p}+Z_{P}=0
\end{array}\right\} . \\
\text { Equilibrium equation of model: }\left\{\begin{array}{l}
\left(\frac{\partial \sigma_{x}}{\partial x}\right)_{m}+\left(\frac{\partial \tau_{y x}}{\partial y}\right)_{m}+\left(\frac{\partial \tau_{z x}}{\partial z}\right)_{m}+X_{m}=0 \\
\left(\frac{\partial \sigma_{z}}{\partial z}\right)_{m}+\left(\frac{\partial \tau_{z y}}{\partial z}\right)_{m}+\left(\frac{\partial \tau_{x y}}{\partial x}\right)_{m}+Y_{m}=0 \\
\left(\frac{\partial \tau_{y z}}{\partial y}\right)_{m}+Z_{m}=0
\end{array}\right\} .
\end{array}
$$

Substitute the symmetry coefficient $c_{\sigma}, c_{L}, c_{X}$ into formula (1), and the following formula is obtained:

$$
\left\{\begin{array}{c}
\left(\frac{\partial \sigma_{x}}{\partial x}\right)_{m}+\left(\frac{\partial \tau_{y x}}{\partial y}\right)_{m}+\left(\frac{\partial \tau_{z x}}{\partial z}\right)_{m}+\frac{c_{\gamma} c_{L}}{c_{\sigma}} X_{m}=0 \\
\left(\frac{\partial \sigma_{y}}{\partial y}\right)_{m}+\left(\frac{\partial \tau_{z y}}{\partial z}\right)_{m}+\left(\frac{\partial \tau_{x y}}{\partial x}\right)_{m}+\frac{c_{\gamma} c_{L}}{c_{\sigma}} Y_{m}=0 \\
\left(\frac{\partial \sigma_{z}}{\partial z}\right)_{m}+\left(\frac{\partial \tau_{x z}}{\partial x}\right)_{m}+\left(\frac{\partial \tau_{y z}}{\partial y}\right)_{m}+\frac{c_{\gamma} c_{L}}{c_{\sigma}} Z_{m}=0
\end{array}\right\} .
$$

According to formulas (2) and (3), we can get the equation for $c_{\gamma}, c_{L}, c_{\sigma}$.

$$
\frac{c_{\gamma} c_{L}}{c_{\sigma}}=1 .
$$

(2) Establish a symmetrical condition by the geometry equation: 


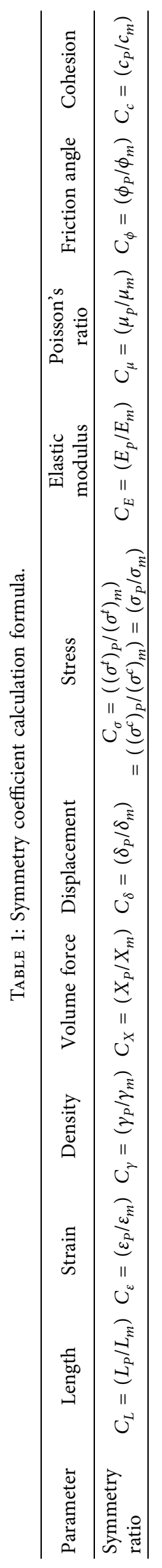




$$
\text { Geometry equation of prototype: }\left\{\begin{array}{c}
\left(\varepsilon_{x}\right)_{p}=\left(\frac{\partial u}{\partial x}\right)_{p} \\
\left(\varepsilon_{y}\right)_{p}=\left(\frac{\partial v}{\partial y}\right)_{p} \\
\left(\varepsilon_{z}\right)_{p}=\left(\frac{\partial w}{\partial z}\right)_{p} \\
\left(\gamma_{x y}\right)_{p}=\left(\frac{\partial u}{\partial y}\right)_{p}+\left(\frac{\partial v}{\partial x}\right)_{p} \\
\left(\gamma_{y z}\right)_{p}=\left(\frac{\partial v}{\partial z}\right)_{p}+\left(\frac{\partial w}{\partial y}\right)_{p} \\
\left(\gamma_{z x}\right)_{p}=\left(\frac{\partial u}{\partial z}\right)_{p}+\left(\frac{\partial w}{\partial x}\right)_{p}
\end{array}\right\} .
$$

Substitute the symmetry coefficient $c_{\varepsilon}, c_{\delta}, c_{L}$ into formula (5), and the following formula is obtained:

$$
\left\{\begin{array}{c}
\left(\varepsilon_{x}\right)_{m}\left(\frac{c_{\xi} c_{L}}{c_{\delta}}\right)=\left(\frac{\partial u}{\partial x}\right)_{m} \\
\left(\varepsilon_{y}\right)_{m}\left(\frac{c_{\xi} c_{L}}{c_{\delta}}\right)=\left(\frac{\partial v}{\partial y}\right)_{m} \\
\left(\varepsilon_{z}\right)_{m}\left(\frac{c_{\xi} c_{L}}{c_{\delta}}\right)=\left(\frac{\partial w}{\partial z}\right)_{m} \\
\left(\gamma_{x y}\right)_{m}\left(\frac{c_{\xi} c_{L}}{c_{\delta}}\right)=\left(\frac{\partial u}{\partial y}\right)_{m}+\left(\frac{\partial v}{\partial x}\right)_{m} \\
\left(\gamma_{y z}\right)_{m}\left(\frac{c_{\xi} c_{L}}{c_{\delta}}\right)=\left(\frac{\partial v}{\partial z}\right)_{m}+\left(\frac{\partial w}{\partial y}\right)_{m} \\
\left(\gamma_{z x}\right)_{m}\left(\frac{c_{\xi} c_{L}}{c_{\delta}}\right)=\left(\frac{\partial u}{\partial z}\right)_{m}+\left(\frac{\partial w}{\partial x}\right)_{m}
\end{array}\right\} .
$$


According to formulas (6) and (7), we can get the equation for $c_{\xi}, c_{\delta}, c_{L}$.

$$
\frac{c_{\xi} c_{L}}{c_{\delta}}=1
$$

(3) Establish a symmetrical condition by the physical equation:

$$
\begin{aligned}
& \text { Physical equation of prototype : }\left\{\begin{array}{c}
\left(\varepsilon_{x}\right)_{p}=\frac{1}{E_{P}}\left[\sigma_{x}-\mu\left(\sigma_{y}+\sigma_{z}\right)\right]_{p} \\
\left(\varepsilon_{y}\right)_{p}=\frac{1}{E_{P}}\left[\sigma_{y}-\mu\left(\sigma_{x}+\sigma_{z}\right)\right]_{p} \\
\left(\varepsilon_{z}\right)_{p}=\frac{1}{E_{P}}\left[\sigma_{z}-\mu\left(\sigma_{x}+\sigma_{y}\right)\right]_{p} \\
\left(\gamma_{x y}\right)_{p}=\left[\frac{2(1+\mu)}{E_{p}} \tau_{x y}\right]_{p} \\
\left(\gamma_{x z}\right)_{p}=\left[\frac{2(1+\mu)}{E_{p}} \tau_{x z}\right]_{p} \\
\left(\gamma_{y z}\right)_{p}=\left[\frac{2(1+\mu)}{E_{p}} \tau_{y z}\right]_{p}
\end{array}\right\} \\
& \text { Physical equation of model : }\left\{\begin{array}{c}
\left(\varepsilon_{x}\right)_{m}=\frac{1}{E_{P}}\left[\sigma_{x}-\mu\left(\sigma_{y}+\sigma_{z}\right)\right]_{m} \\
\left(\varepsilon_{y}\right)_{m}=\frac{1}{E_{P}}\left[\sigma_{y}-\mu\left(\sigma_{x}+\sigma_{z}\right)\right]_{m} \\
\left(\varepsilon_{z}\right)_{m}=\frac{1}{E_{P}}\left[\sigma_{z}-\mu\left(\sigma_{x}+\sigma_{y}\right)\right]_{m} \\
\left(\gamma_{x y}\right)_{m}=\left[\frac{2(1+\mu)}{E_{p}} \tau_{x y}\right]_{m} \\
\left(\gamma_{x z}\right)_{m}=\left[\frac{2(1+\mu)}{E_{p}} \tau_{x z}\right]_{m} \\
\left(\gamma_{y z}\right)_{m}=\left[\frac{2(1+\mu)}{E_{p}} \tau_{y z}\right]_{m}
\end{array}\right\} .
\end{aligned}
$$

Substitute the symmetrical coefficient $c_{\varepsilon}, c_{\sigma}, c_{\mu}, c_{E}$ into formula (9), and the following formula is obtained. 


$$
\left\{\begin{array}{c}
\left(\varepsilon_{x}\right)_{m}=\frac{c_{\sigma}}{c_{\varepsilon} c_{E}} \frac{1}{E_{m}}\left[\sigma_{x}-c_{\mu} \mu\left(\sigma_{y}+\sigma_{z}\right)\right]_{m} \\
\left(\varepsilon_{y}\right)_{m}=\frac{c_{\sigma}}{c_{\varepsilon} c_{E}} \frac{1}{E_{m}}\left[\sigma_{y}-c_{\mu} \mu\left(\sigma_{x}+\sigma_{z}\right)\right]_{m} \\
\left(\varepsilon_{z}\right)_{m}=\frac{c_{\sigma}}{c_{\varepsilon} c_{E}} \frac{1}{E_{m}}\left[\sigma_{z}-c_{\mu} \mu\left(\sigma_{x}+\sigma_{y}\right)\right]_{m} \\
\left(\gamma_{x y}\right)_{m}=\frac{c_{\sigma}}{c_{\varepsilon} c_{E}}\left[\frac{2(1+\mu)}{E_{p}} \tau_{x y}\right]_{m} \\
\left(\gamma_{x z}\right)_{m}=\frac{c_{\sigma}}{c_{\varepsilon} c_{E}}\left[\frac{2(1+\mu)}{E_{p}} \tau_{x z}\right]_{m} \\
\left(\gamma_{y z}\right)_{m}=\frac{c_{\sigma}}{c_{\varepsilon} c_{E}}\left[\frac{2(1+\mu)}{E_{p}} \tau_{y z}\right]_{m}
\end{array}\right\} .
$$

According to formulas (10) and (11), we get the equation for $c_{\sigma}, c_{\varepsilon}, c_{E}$. The symmetry coefficient of Poisson's is $c_{\mu}=1$.

$$
\frac{c_{\sigma}}{c_{\varepsilon} c_{E}}=1
$$

2.1.3. Symmetry Ratio Determination. According to the symmetry theory and the size of model box, finally the symmetry ratio in the model test is $C_{L}=16: 1$. It is assumed that the symmetry ratio of density is $1: 1$, and the dimensionless parameter is $1: 1$. Therefore, all of the parameters of symmetry ratio in the model test are given in Table 2.

\section{Testing}

\subsection{Selecting of Stratum Symmetry Materials}

3.1.1. Prototype Stratum Parameters. In the model test, selecting the soil of Shanghai is considered as the prototype stratum. The information of prototype stratum in Shanghai is given in Table 3. According to formula (13), the relationship between compression modulus and elastic modulus is

$$
E=E_{S}\left(1-\frac{2 \mu^{2}}{1-\mu}\right),
$$

where $E$ is the elastic modulus of soil, $\mathrm{kPa} ; E_{S}$ is the compression modulus of soil, $\mathrm{kPa} ; \mu$ is Poisson's ratio of soil.

Based on the exiting conclusion of research, finally, it selected mixed materials to research stratum in the model test, including iron ore powder, natural sands, gypsum, and lime. The iron ore powder and natural sands are aggregate, which have a great density. The gypsum and lime is the adhesive, which has better sticky property and great tension. In addition, the mixed materials are no harm for beings, easily available, low cost, and so on.
3.1.2. Determination of Mixed Materials Ratio Initially. According to the direct shear test for many times, rely on the density of symmetry ratio. The mixed materials ratio is obtained initially, as given in Table 4 . The mixed materials are made to simulate each stratum, as given in Table 5 .

From what has been researched above, it just studies about the mixed materials ratio for silty clay and silt soil.

\subsection{Determination of Mechanics Parameters for Stratum Symmetry Materials}

3.2.1. Design of the Orthogonal Test. The orthogonal test is used to research the proportion of mixed materials, design three factors and three levels, a total of nine tests, according to the purpose of the test, considering the density, cohesion, friction angle, elastic modulus, and Poisson's ratio as the control index, as given in Table 6 .

3.2.2. Parameters of the Orthogonal Test. In order to get the five parameters, that is, density, cohesion, friction angle, elastic modulus, and Poisson's ratio, the research adopts, respectively, the density test, the direct shear test, elastic modulus test, and Poisson's ratio test.

(1) Density test

In the density test, the formula of density is given in the following equation, and the instruments are given in Table 7.

$$
\rho=\frac{m_{1}-m_{2}}{V_{2}}
$$

$\rho$ is the density of soil, $\mathrm{g} / \mathrm{cm}^{3} ; m_{1}$ is the total quality of soil and ring knife, $g ; m_{2}$ is the quality of ring knife, $g$; $V_{2}$ is the volume of ring knife, $\mathrm{cm}^{3}$.

(2) Direct shear test

The direct shear test is a common method to measure the shear strength of soil. There is about four times to measure the shear strength in one direct shear test, under different vertical pressures, measuring the shear stress when soil is destroyed. The formula is given as follows:

$$
\tau_{f}=c+\sigma \tan \phi
$$

$\tau_{f}$ is the shear strength of soil, $\mathrm{kPa}$; $c$ is the cohesion of soil, $\mathrm{kPa} ; \phi$ is the friction angle of soil; $\sigma$ is the vertical stress, $\mathrm{kPa}$.

(3) Poisson's ratio and the elastic modulus test The value of Poisson's ratio is measured by two steps:

(a) The lateral pressure coefficient $K_{0}$ of soil samples is obtained by the static pressure coefficient test

(b) Getting the value of Poisson's ratio according to the generalized Hooker's law

The elastic modulus is measured from the lateral compression test of similar materials, as shown in Figure 1, and the formula is derived as follows: 
TABLE 2: Each of parameter for symmetry ratio.

\begin{tabular}{lccccccccc}
\hline Parameter & Geometry & Displacement & Stress & Strain & Cohesion & Friction angle & Elastic modulus & Poisson's ratio & Bending moment \\
\hline Prototype & 16 & 16 & 16 & 1 & 16 & 1 & 16 & 1 & $16^{4}$ \\
Model & 1 & 1 & 1 & 1 & 1 & 1 & 1 & 1 & 1 \\
\hline
\end{tabular}

TABLE 3: The physical quantity of prototype stratum in Shanghai.

\begin{tabular}{lcccccc}
\hline Stratum & Density $\left(\mathrm{kN} / \mathrm{m}^{3}\right)$ & Cohesion $(\mathrm{kPa})$ & Friction angle $\left(^{\circ}\right)$ & Elastic modulus $(\mathrm{MPa})$ & Poisson's ratio & Thickness of stratum $(\mathrm{m})$ \\
\hline Fill the soil & 18.5 & 0 & 15 & 11 & 0.33 & 0.64 \\
Silty clay & 19.2 & 20 & 17 & 38 & 0.36 & 1.92 \\
Silt soil & 17.5 & 13 & 11 & 10 & 0.31 & 17.6 \\
Silty clay & 18.4 & 27 & 14 & 42 & 0.34 & 6.24 \\
\hline
\end{tabular}

TAвLE 4: Mixed materials finished initially.

\begin{tabular}{lccc}
\hline $\begin{array}{l}\text { Proportion of iron and sand in } \\
\text { mixture (\%) }\end{array}$ & $\begin{array}{c}\text { Quality ratio between iron } \\
\text { and sand }\end{array}$ & $\begin{array}{c}\text { Quality ratio between gypsum } \\
\text { and lime }\end{array}$ & $\begin{array}{c}\text { Volume ratio between water and } \\
\text { gypsum }\end{array}$ \\
\hline 85 & $1.5: 3.5$ & $1: 1$ & $2: 8$ \\
\hline
\end{tabular}

TABLE 5: Simulation materials of each stratigraphic.

\begin{tabular}{lccc}
\hline Stratum & Thickness of prototype $(\mathrm{m})$ & Thickness of the model $(\mathrm{cm})$ & Mixed materials \\
\hline Fill the soil & 0.64 & 4 & Natural sands \\
Silty clay & 1.92 & 12 & Iron ore powder, natural sands, gypsum, and lime \\
Silt soil & 17.6 & 110 & Iron ore powder, natural sands, gypsum, and lime \\
Silty clay & 6.24 & 39 & Iron ore powder, natural sands, gypsum, and lime \\
\hline
\end{tabular}

TABLE 6: Value of control index.

\begin{tabular}{lccc}
\hline Factors & Proportion of iron and sand in mixture (\%) & Quality ratio between iron and sand & Quality ratio between gypsum and lime \\
\hline Level 1 & 80 & $2: 3$ & $2: 1$ \\
Level 2 & 85 & $1.5: 3.5$ & $1: 1$ \\
Level 3 & 90 & $1: 4$ & $1: 2$ \\
\hline
\end{tabular}

TABLE 7: Instrument of the density test.

\begin{tabular}{lcccc}
\hline Name & Ring knife & Balance & Vernier caliper & Compaction meter \\
\hline \multirow{2}{*}{ Parameters } & Internal diameter, 6-8 cm; height & Accuracy, & Accuracy, & Diameter, $100 \mathrm{~mm} ;$ height, $127 \mathrm{~mm} ;$ volume, \\
& $2 \mathrm{~cm}$ & $0.1 \mathrm{~g}$ & $0.02 \mathrm{~mm}$ & $997 \mathrm{~cm}^{3}$ \\
\hline
\end{tabular}

According to generalized Hooke's law,

$$
\begin{aligned}
\varepsilon_{x}+\varepsilon_{y} & =0, \\
\varepsilon_{x} & =\frac{\sigma_{x}}{E}-\frac{\mu\left(\sigma_{y}+\sigma_{z}\right)}{E}, \\
\varepsilon_{y} & =\frac{\sigma_{y}}{E}-\frac{\mu\left(\sigma_{x}+\sigma_{z}\right)}{E} .
\end{aligned}
$$

Substituting formulas (17) and (18) into formula (16), the following equation is obtained:

$$
K_{0}=\frac{\sigma_{x}}{\sigma_{z}}=\frac{\mu}{1-\mu}
$$

where $\mu$ is Poisson's ratio; $K_{0}$ is the side pressure coefficient; $E$ is the elastic modulus, $\mathrm{kPa}$.
According to generalized Hooke's law, the strain of $Z$ axis is given in the following formula:

$$
\varepsilon_{z}=\frac{\sigma_{z}}{E}-\frac{\mu\left(\sigma_{x}+\sigma_{y}\right)}{E} .
$$

Substituting $\sigma_{z}=p, \sigma_{x}=\sigma_{y}=(\mu /(1-\mu)) p$ into formula (20), the following equation is obtained:

$$
\begin{gathered}
E=\frac{P}{\varepsilon_{Z}}\left(1-\frac{2 \mu^{2}}{1-\mu}\right), \\
\varepsilon_{Z}=\frac{\Delta H}{H}=\frac{\left(e_{0}-e_{1}\right)}{\left(1+e_{0}\right)} .
\end{gathered}
$$
is 


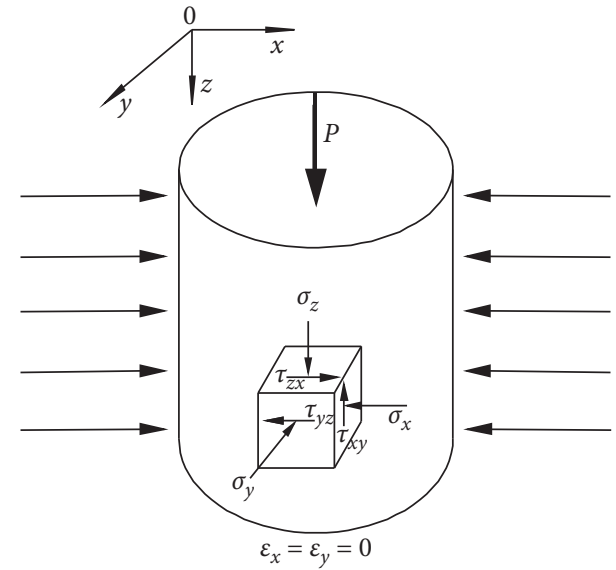

FIgURE 1: Stress condition of the confined compress test.

$$
a=\frac{\Delta e}{\Delta \sigma}=\frac{\left(e_{0}-e_{1}\right)}{P} .
$$

Finally, formula (21) is given as follows:

$$
E=\frac{1+e_{0}}{a}\left(1-\frac{2 \mu^{2}}{1-\mu}\right) .
$$

Compression modulus under confinement conditions is

$$
\begin{aligned}
E_{S} & =\frac{1+e_{0}}{a}, \\
E & =E_{S}\left(1-\frac{2 \mu^{2}}{1-\mu}\right),
\end{aligned}
$$

where $E_{S}$ is the compression modulus under confinement conditions, $\mathrm{kPa} ; e_{0}$ is the porosity ratio; $a$ is the compression coefficient under confinement conditions, $\mathrm{kPa}^{-1} ; \Delta e$ is the change of the amount porosity ratio; $\Delta \sigma$ is the change of the amount vertical stress, $\mathrm{kPa}$.

\section{Results and Analysis}

According to design and the performed orthogonal test, the results of the orthogonal test obtained are given in Table 8 .

Because the value of density almost has no change, as well as Poisson's ratio, they are out of consideration in the following test.

First of all, to produce the mixed materials, select the cohesive force, the friction angle, and the elastic modulus as the control factor.

4.1. Analysis of Cohesive Force as the Control Factor. According to the results of the orthogonal test for nine group data, calculate the relative error of nine group cohesive data. The smaller the value of relative error, the more accurate the results, as given in Table 9.

According to the orthogonal test and relative error of cohesive, the dispersion of factors for $A, B$, and $C$ is
$A:\left(\mathrm{I}_{A}-\delta\right)^{2}+\left(\mathrm{II}_{A}-\delta\right)^{2}+\left(\mathrm{III}_{A}-\delta\right)^{2}=112.92$,
$B:\left(\mathrm{I}_{B}-\delta\right)^{2}+\left(\mathrm{II}_{B}-\delta\right)^{2}+\left(\mathrm{III}_{B}-\delta\right)^{2}=14.82$,
$C:\left(\mathrm{I}_{C}-\delta\right)^{2}+\left(\mathrm{II}_{C}-\delta\right)^{2}+\left(\mathrm{III}_{C}-\delta\right)^{2}=35.25$. that

From the test results analysis and Figure 2, we can see

(a) The relationship between the $A, B$, and $C$ is $A>C>B$

(b) The factor 2 point is inflection point, and the line changes suddenly when through the factor 2 point.

(c) $A 1, B 2, C 2$ is the closest value, respectively, in each factor compared with the prototype cohesion value

4.2. Analysis of Friction Angle as the Control Factor. According to the results of the orthogonal test for nine group data, calculate the relative error of nine group friction angle data. The smaller the value of relative error, the more accurate the results, as given in Table 10 .

According to the orthogonal test and relative error of friction angle, the dispersion of factors for $A, B$, and $C$ is
$A:\left(\mathrm{I}_{A}-\delta\right)^{2}+\left(\mathrm{II}_{A}-\delta\right)^{2}+\left(\mathrm{III}_{A}-\delta\right)^{2}=0.0481$,
$B:\left(\mathrm{I}_{B}-\delta\right)^{2}+\left(\mathrm{II}_{B}-\delta\right)^{2}+\left(\mathrm{III}_{B}-\delta\right)^{2}=0.0065$,
$C:\left(\mathrm{I}_{C}-\delta\right)^{2}+\left(\mathrm{II}_{C}-\delta\right)^{2}+\left(\mathrm{III}_{C}-\delta\right)^{2}=0.0099$.

From the test results analysis and Figure 3, we can see that

(a) The relationship between the $A, B$, and $C$ is $A>B>C$

(b) The factor 2 point is inflection point, and the line changes suddenly when through the factor 2 point.

(c) $A 2, B 3, C 1$ is the closest value, respectively, in each factor for the prototype friction angle value

4.3. Analysis of Elastic Modulus as the Control Factor. According to the results of the orthogonal test for nine group data, calculate the relative error of nine group elastic modulus data. The smaller the value of relative error, the more accurate the results, as given in Table 11 .

According to the orthogonal test and relative error of elastic modulus, the dispersion of factors for $A, B$, and $C$ is

$$
\begin{aligned}
& A:\left(\mathrm{I}_{A}-\delta\right)^{2}+\left(\mathrm{II}_{A}-\delta\right)^{2}+\left(\mathrm{III}_{A}-\delta\right)^{2}=50.27 \\
& B:\left(\mathrm{I}_{B}-\delta\right)^{2}+\left(\mathrm{II}_{B}-\delta\right)^{2}+\left(\mathrm{III}_{B}-\delta\right)^{2}=9.14 \\
& C:\left(\mathrm{I}_{C}-\delta\right)^{2}+\left(\mathrm{II}_{C}-\delta\right)^{2}+\left(\mathrm{III}_{C}-\delta\right)^{2}=207.40 .
\end{aligned}
$$

From the test results analysis and Figure 4, we can see that

(a) The relationship between the $A, B$, and $C$ is $C>A>B$

(b) The factor 2 point is inflection point, and the line changes suddenly when through the factor 2 point.

(c) $A 3, B 2, C 1$ is the closest value, respectively, in each factor for the prototype elastic modulus value

As shown in Figures 5 and 6, according to the standard, the samples are damaged when the displacement of 
TABLE 8: Orthogonal test conclusion.

\begin{tabular}{|c|c|c|c|c|c|c|c|c|}
\hline $\begin{array}{l}\text { Serial } \\
\text { number }\end{array}$ & $\begin{array}{l}\text { Proportion of iron } \\
\text { and sand in mixture } \\
(\%)\end{array}$ & $\begin{array}{c}\text { Quality ratio } \\
\text { between iron } \\
\text { and sand } \\
\end{array}$ & $\begin{array}{c}\text { Quality ratio } \\
\text { between gypsum } \\
\text { and lime } \\
\end{array}$ & $\begin{array}{c}\text { Elastic } \\
\text { modulus } \\
(\mathrm{MPa})\end{array}$ & $\begin{array}{l}\text { Cohesion } \\
\quad(\mathrm{kPa})\end{array}$ & $\begin{array}{l}\text { Friction } \\
\text { angle }\left({ }^{\circ}\right)\end{array}$ & $\begin{array}{l}\text { Density } \\
\left(\mathrm{g} / \mathrm{cm}^{3}\right)\end{array}$ & $\begin{array}{l}\text { Poisson's } \\
\text { ratio }\end{array}$ \\
\hline$\overline{1}$ & 80 & $2: 3$ & $2: 1$ & 9.76 & 16 & 29 & 2.24 & 0.30 \\
\hline 2 & 80 & $1.5: 3.5$ & $1: 1$ & 17.95 & 2.8 & 31.28 & 2.16 & 0.35 \\
\hline 3 & 80 & $1: 4$ & $1: 2$ & 23.78 & 16.05 & 28.80 & 2.11 & 0.37 \\
\hline 4 & 85 & $2: 3$ & $1: 1$ & 19.94 & 29.69 & 26.60 & 2.28 & 0.34 \\
\hline 5 & 85 & $1.5: 3.5$ & $1: 2$ & 21.56 & 22.87 & 27.19 & 2.17 & 0.36 \\
\hline 6 & 85 & $1: 4$ & $2: 1$ & 8.43 & 27.29 & 25.11 & 2.05 & 0.31 \\
\hline 7 & 90 & $2: 3$ & $1: 2$ & 16.37 & 20.06 & 27.91 & 2.25 & 0.35 \\
\hline 8 & 90 & $1.5: 3.5$ & $2: 1$ & 2.48 & 24.48 & 27.58 & 2.15 & 0.30 \\
\hline 9 & 90 & $1: 4$ & $1: 1$ & 13.68 & 10.43 & 28.48 & 2.09 & 0.33 \\
\hline
\end{tabular}

TABLE 9: Cohesive force of relative error analysis.

\begin{tabular}{|c|c|c|c|c|}
\hline $\begin{array}{l}\text { Serial } \\
\text { number }\end{array}$ & $\begin{array}{c}\text { Proportion of iron and sand in } \\
\text { mixture (\%) }\end{array}$ & $\begin{array}{l}\text { Quality ratio between iron and } \\
\text { sand }\end{array}$ & $\begin{array}{l}\text { Quality ratio between gypsum } \\
\text { and lime }\end{array}$ & Relative error \\
\hline 1 & 80 & $2: 3$ & $2: 1$ & 15 \\
\hline 2 & 80 & $1.5: 3.5$ & $1: 1$ & 1.8 \\
\hline 3 & 80 & $1: 4$ & $1: 2$ & 15.05 \\
\hline 4 & 85 & $2: 3$ & $1: 1$ & 28.69 \\
\hline 5 & 85 & $1.5: 3.5$ & $1: 2$ & 21.87 \\
\hline 6 & 85 & $1: 4$ & $2: 1$ & 26.29 \\
\hline 7 & 90 & $2: 3$ & $1: 2$ & 19.06 \\
\hline 8 & 90 & $1.5: 3.5$ & $2: 1$ & 23.48 \\
\hline 9 & 90 & $1: 4$ & $1: 1$ & 9.43 \\
\hline I & 10.62 & 20.92 & 21.59 & $P=160.68$ \\
\hline II & 25.62 & 15.72 & 13.31 & \\
\hline III & 17.32 & 16.92 & 18.66 & $\delta=P / 9=17.85$ \\
\hline
\end{tabular}

$P$, the sum of the data for every factor; $\delta$, the average of the data for every factor; I, the average of relative error for factor $1 ; \mathrm{II}$, the average of relative error for factor 2; III, the average of relative error for factor 3.

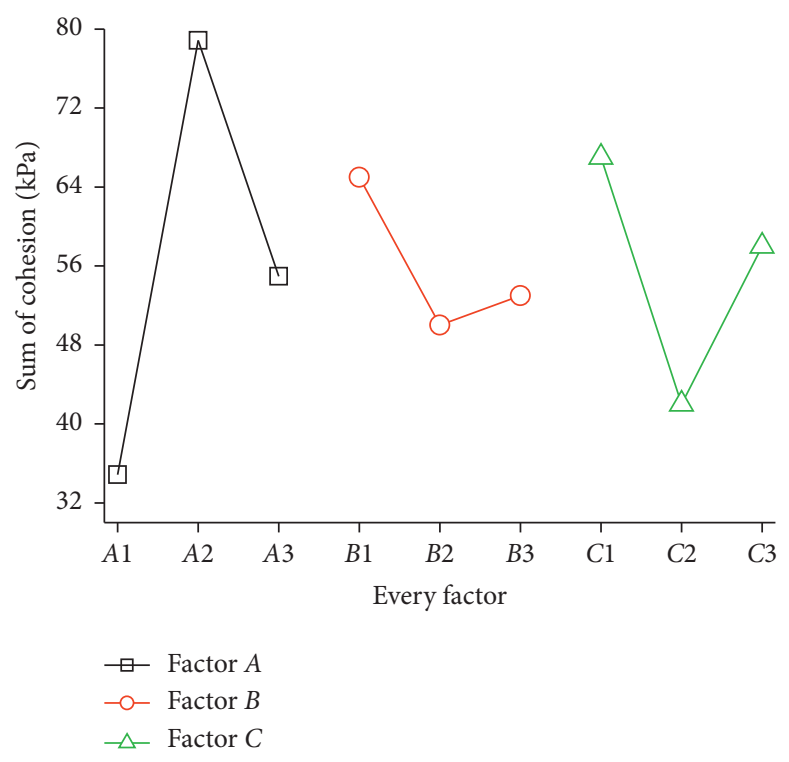

Figure 2: Cohesive force of trend diagram. 
TABLE 10: Friction angle of relative error analysis.

\begin{tabular}{|c|c|c|c|c|}
\hline $\begin{array}{l}\text { Serial } \\
\text { number }\end{array}$ & $\begin{array}{c}\text { Proportion of iron and sand in } \\
\text { mixture (\%) }\end{array}$ & $\begin{array}{l}\text { Quality ratio between iron and } \\
\text { sand }\end{array}$ & $\begin{array}{l}\text { Quality ratio between gypsum and } \\
\text { lime }\end{array}$ & Relative error \\
\hline 1 & 80 & $2: 3$ & $2: 1$ & 1.64 \\
\hline 2 & 80 & $1.5: 3.5$ & $1: 1$ & 1.84 \\
\hline 3 & 80 & $1: 4$ & $1: 2$ & 1.62 \\
\hline 4 & 85 & $2: 3$ & $1: 1$ & 1.42 \\
\hline 5 & 85 & $1.5: 3.5$ & $1: 2$ & 1.47 \\
\hline 6 & 85 & $1: 4$ & $2: 1$ & 1.28 \\
\hline 7 & 90 & $2: 3$ & $1: 2$ & 1.54 \\
\hline 8 & 90 & $1.5: 3.5$ & $2: 1$ & 1.51 \\
\hline 9 & 90 & $1: 4$ & $1: 1$ & 1.59 \\
\hline I & 1.7 & 1.53 & 1.48 & $P=13.92$ \\
\hline II & 1.39 & 1.61 & 1.62 & $\delta=P / 9=155$ \\
\hline III & 1.55 & 1.50 & 1.54 & $\delta=P / 9=1.55$ \\
\hline
\end{tabular}

$P$, the sum of the data for every factor; $\delta$, the average of the data for every factor; I, the average of relative error for factor $1 ; \mathrm{II}$, the average of relative error for factor 2; III, the average of relative error for factor 3 .

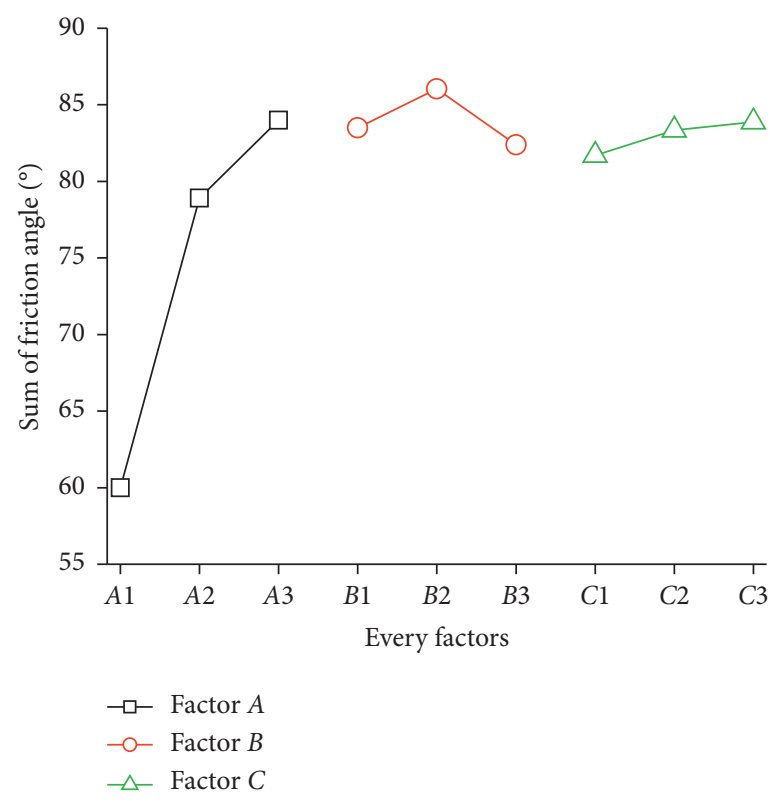

Figure 3: Friction angle of trend diagram.

TABLE 11: Elastic modulus of relative error analysis.

\begin{tabular}{|c|c|c|c|c|}
\hline $\begin{array}{l}\text { Serial } \\
\text { number }\end{array}$ & $\begin{array}{c}\text { Proportion of iron and sand in } \\
\text { mixture }(\%)\end{array}$ & $\begin{array}{l}\text { Quality ratio between iron and } \\
\text { sand }\end{array}$ & $\begin{array}{l}\text { Quality ratio between gypsum } \\
\text { and lime }\end{array}$ & Relative error \\
\hline 1 & 80 & $2: 3$ & $2: 1$ & 12.94 \\
\hline 2 & 80 & $1.5: 3.5$ & $1: 1$ & 24.64 \\
\hline 3 & 80 & $1: 4$ & $1: 2$ & 32.97 \\
\hline 4 & 85 & $2: 3$ & $1: 1$ & 27.49 \\
\hline 5 & 85 & $1.5: 3.5$ & $1: 2$ & 29.8 \\
\hline 6 & 85 & $1: 4$ & $2: 1$ & 11.04 \\
\hline 7 & 90 & $2: 3$ & $1: 2$ & 22.39 \\
\hline 8 & 90 & $1.5: 3.5$ & $2: 1$ & 2.54 \\
\hline 9 & 90 & $1: 4$ & $1: 1$ & 18.54 \\
\hline I & 23.52 & 20.94 & 8.84 & $P=182.36$ \\
\hline II & 22.78 & 18.99 & 23.56 & $\delta=P / 9=2026$ \\
\hline III & 14.49 & 20.85 & 28.39 & $\delta=P / 9=20.26$ \\
\hline
\end{tabular}

$P$, the sum of the data for every factor; $\delta$, the average of the data for every factor; I, the average of relative error for factor $1 ;$ II, the average of relative error for factor 2; III, the average of relative error for factor 3 . 


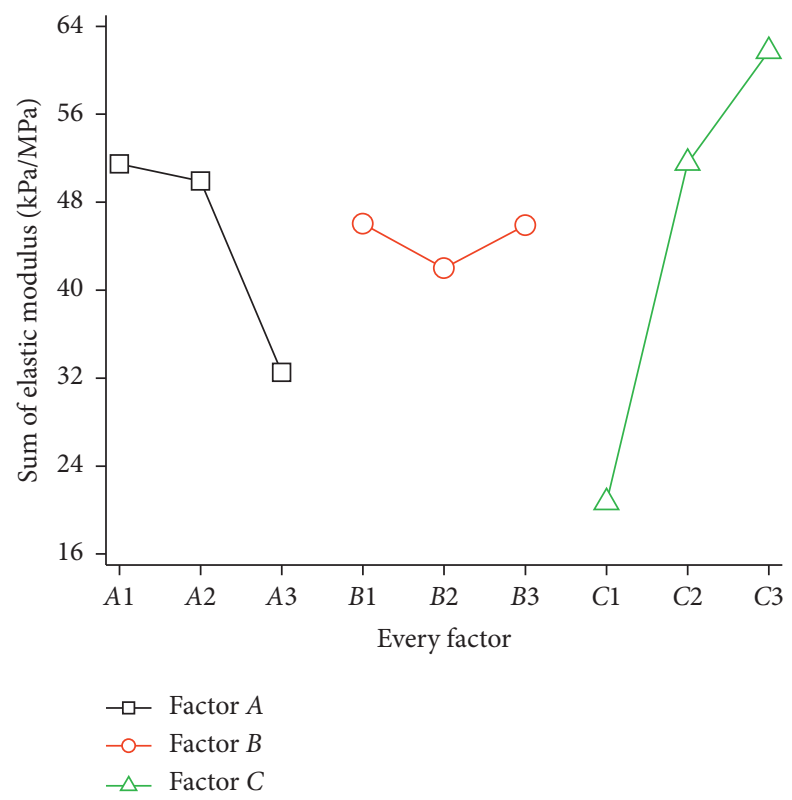

Figure 4: Elastic modulus of trend diagram.

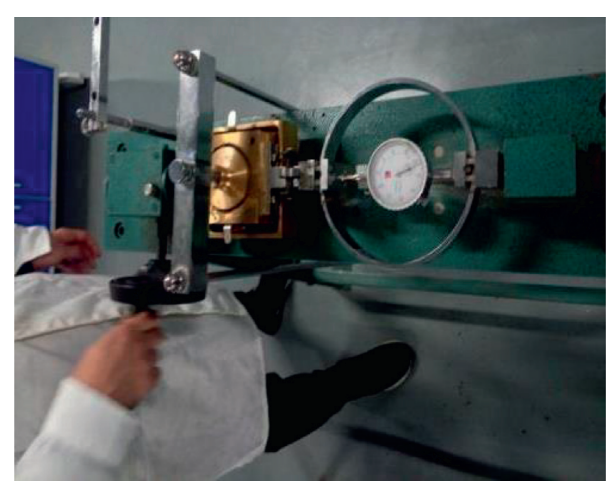

Figure 5: Action cycle of direct shear apparatus.

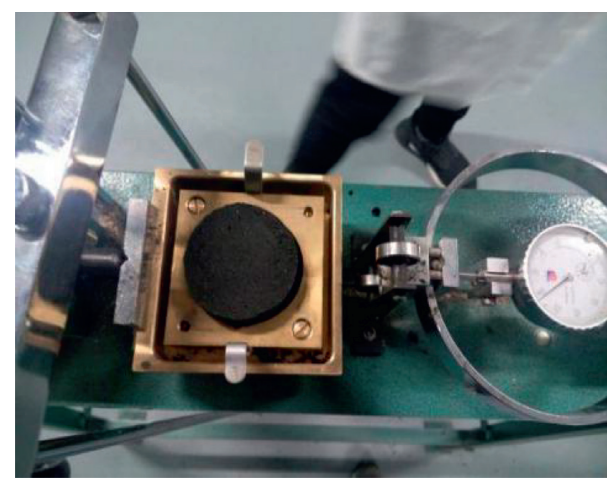

FIGURE 6: Failure model of test piece.

samples has no change obviously in the direct shear test. Finally, the proportion of mixed materials is shown in Figure 7. Based on the above three control factors, use the direct shear test to get the proportion of mixed materials, as given in Table 12 .
Use the parameters of mixed materials to compare with the parameters of the prototype and model. It is proved that the proportion of mixed materials is reasonable and meets the requirements of symmetry ratio, as given in Tables 13 and 14 . 


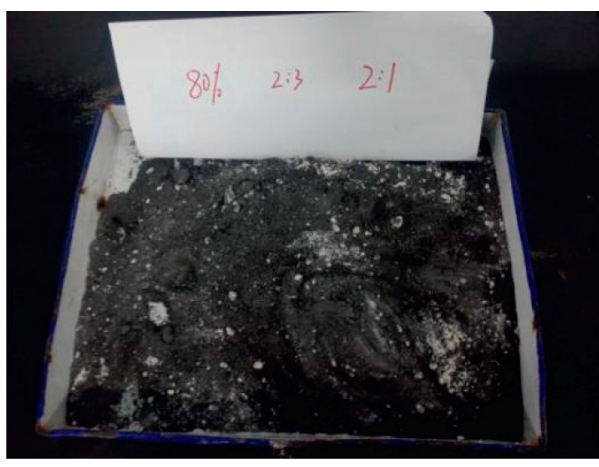

(a)

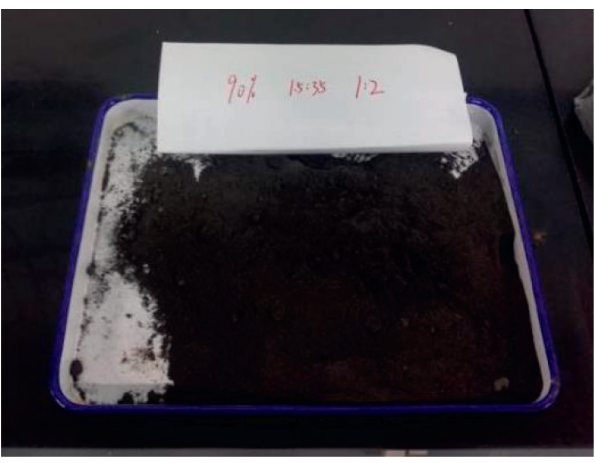

(b)

Figure 7: Proportion of mixed materials.

TABLE 12: Mixed material proportion table.

\begin{tabular}{lccc}
\hline $\begin{array}{l}\text { Mixed } \\
\text { materials }\end{array}$ & Proportion of iron and sand in mixture (\%) & $\begin{array}{c}\text { Quality ratio between iron and } \\
\text { sand }\end{array}$ & $\begin{array}{c}\text { Quality ratio between gypsum and } \\
\text { lime }\end{array}$ \\
\hline Silt soil & 80 & $2: 3$ & $2: 1$ \\
Silty clay & 90 & $1.5: 3.5$ & $1: 2$ \\
\hline
\end{tabular}

TABLE 13: Comparison of physical mechanical parameters for silty clay.

\begin{tabular}{lccccc}
\hline Materials & Elastic modulus $(\mathrm{MPa})$ & Density $\left(\mathrm{kN} / \mathrm{m}^{3}\right)$ & Cohesion $(\mathrm{kPa})$ & Friction angle $\left(^{\circ}\right)$ & Poisson's ratio \\
\hline Prototype & 30.8 & 19.8 & 29 & 15 & 0.36 \\
Model & 1.92 & 19.8 & 1.81 & 15 & 0.36 \\
Test & 2.08 & 21.03 & 1.98 & 20.36 \\
\hline
\end{tabular}

TABLE 14: Comparison of physical mechanical parameters for silt soil.

\begin{tabular}{lccccc}
\hline Materials & Elastic modulus $(\mathrm{MPa})$ & Density $\left(\mathrm{kN} / \mathrm{m}^{3}\right)$ & Cohesion $(\mathrm{kPa})$ & Friction angle $\left(^{\circ}\right)$ & Poisson's ratio \\
\hline Prototype & 10 & 17.5 & 13 & 11 & 0.31 \\
Model & 0.7 & 17.5 & 1 & 11 & 0.31 \\
Test & 0.95 & 18.7 & 2.11 & 12.21 & 0.34 \\
\hline
\end{tabular}

\section{Conclusion}

(1) According to the symmetry theory, establish the equilibrium equation, geometric equation, and physical equation for the prototype and model. The symmetry ration of mixed materials is $16: 1$.

(2) Select the iron ore powder, natural sands, gypsum, and lime to be the mixed materials for model stratum. Use the orthogonal tests to get the proportion of compositions in mixed materials and analyze the results by the deviation.

(3) The proportion of compositions in mixed materials of silt soil is that the proportion of iron and sand in mixture is $80 \%$, the quality ratio between iron and sand is $2: 3$, and the quality ratio between gypsum and lime is $2: 1$.

The proportion of compositions in mixed materials of silty clay is that the proportion of iron and sand in mixture is $90 \%$, the quality ratio between iron and sand is $1.5: 3.5$, and the quality ratio between gypsum and lime is $1: 2$.
It is proved that the proportion of compositions in mixed materials is reasonable and meets the requirements of symmetry ratio compared with the parameters of the prototype and model.

\section{Data Availability}

The data used to support the findings of this study are included within the article.

\section{Conflicts of Interest}

The authors declare that there are no conflicts of interest.

\section{Acknowledgments}

The research was supported by the Fundamental Scientific Research Business Expenses of Provincial Universities in Hebei Province (JQN2020027) and North China University of Science and Technology Doctoral Research Startup Fund (BS201813). 


\section{References}

[1] D. L. Luo, B. Gao, and Y. S. Sheng, "Study on similar materials of surrounding rock in tunnel anti-damping model test," Journal of Shijiazhuang Railway Institute (Natural Science), vol. 21, no. 3, pp. 70-73, 2008.

[2] A. M. Chen, J. C. Gu, and J. Shen, "Application study on the geomechanical model experiment techniques," Chinese Journal of Rock Mechanics and Engineering, vol. 23, no. 22, pp. 3785-3789, 2004.

[3] H. M. Peng, Z. B. Peng, and J. T. Han, "Study on lithologic similar materials," Guangdong Architecture Civil Engineering, vol. 12, no. 12, pp. 12-17, 2002.

[4] E. Fumagalli, Static and Geomechanical Models, China Water Conservancy and Hydropower Press, Beijing, China, 1979.

[5] B. L. Han, X. L. Chen, and Y. L. Song, "Study on similar materials of rock mass," Journal of Wuhan University of Hydraulic and Electrical Engineering, vol. 30, no. 2, pp. 6-9, 1997.

[6] S. P. Wang, Model Test Study on the Tunnel with in Cracked Surrounding Rocks, Zhejiang University, Zhejiang, China, 2004.

[7] X. H. Chen, Brittle Material Structure Model Test, Water Resources and Electricity Press, Beijing, China, 2000.

[8] D. Q. Zuo, The Theory and Method of Model Test, Water Resources and Electricity Press, Beijing, China, 2001.

[9] W. F. Chen, Constitutive Equations for Engineering Materials: Plasticity and Modeling, Vol. 2, Elsevier, Amsterdam, The Netherlands, 1994.

[10] F. Armero and S. Oller, "A general framework for continuum damage models. I. infinitesimal plastic damage models in stress space," International Journal of Solids and Structures, vol. 37, no. 48-50, pp. 7409-7436, 2000.

[11] G. Meschke, R. Lackner, and H. A. Mang, "An anisotropic elastoplastic-damage model for plain concrete," International Journal for Numerical Methods in Engineering, vol. 42, no. 4, pp. 703-727, 1998.

[12] J. Y. Wu, J. Li, and R. Faria, "An energy release rate-based plastic-damage model for concrete," International Journal of Solids and Structures, vol. 43, no. 3-4, pp. 583-612, 2006.

[13] I. Carol, P. C. Prat, and C. M. López, "Normal/shear cracking model: application to discrete crack analysis," Journal of Engineering Mechanics, vol. 123, no. 8, pp. 765-773, 1997.

[14] G. T. Camacho and M. Ortiz, "Computational modelling of impact damage in brittle materials," International Journal of Solids and Structures, vol. 33, no. 20-22, pp. 2899-2938, 1996.

[15] F. Armero, "Large-scale modeling of localized dissipative mechanisms in a local continuum: applications to the numerical simulation of strain localization in rate-dependent inelastic solids," Mechanics of Cohesive-frictional Materials, vol. 4, no. 2, pp. 101-131, 1999.

[16] J.-Y. Wu, "Unified analysis of enriched finite elements for modeling cohesive cracks," Computer Methods in Applied Mechanics and Engineering, vol. 200, no. 45-46, pp. 30313050, 2011.

[17] J.-Y. Wu and S.-L. Xu, "An augmented multicrack elastoplastic damage model for tensile cracking," International Journal of Solids and Structures, vol. 48, no. 18, pp. 2511-2528, 2011.

[18] C. Zhu, K. Zhang, H. Cai et al., "Combined application of optical fibers and CRLD bolts to monitor deformation of a pitin-pit foundation," Advances in Civil Engineering, vol. 2019, Article ID 2572034, 16 pages, 2019.
[19] M. Cervera and J.-Y. Wu, "On the conformity of strong, regularized, embedded and smeared discontinuity approaches for the modeling of localized failure in solids," International Journal of Solids and Structures, vol. 71, pp. 19-38, 2015.

[20] E. Haghighat and S. Pietruszczak, "On modeling of discrete propagation of localized damage in cohesive-frictional materials," International Journal for Numerical and Analytical Methods in Geomechanics, vol. 39, no. 16, pp. 17741790, 2015.

[21] C. Zhu, Z. Yan, Y. Lin, F. Xiong, and Z. Tao, "Design and application of a monitoring system for a deep railway foundation pit project," IEEE Access, vol. 7, pp. 107591107601, 2019.

[22] J. Su, Y. Wang, P. Yang, S. Han, N. Han, and W. Li, "Evaluating and modeling the idb of microencapsulated rejuvenator in aged bitumen by FTIR-ATR tests," Materials, vol. 9, no. 11, pp. 932-947, 2016.

[23] Q.-X. Meng, W.-Y. Xu, H.-L. Wang, X.-Y. Zhuang, W.-C. Xie, and T. Rabczuk, "DigiSim-an open source software package for heterogeneous material modeling based on digital image processing," Advances in Engineering Software, vol. 148, Article ID 102836, 2020.

[24] C. Zhu, M.-c. He, M. Karakus, X.-h. Zhang, and Z. Guo, "The collision experiment between rolling stones of different shapes and protective cushion in open-pit mines," Journal of Mountain Science, vol. 18, no. 5, pp. 1391-1403, 2021.

[25] Q. Yin, J. Y. Wu, C. Zhu, M. C. He, and Q. X. Meng, "Shear mechanical responses of sandstone exposed to high temperature under constant normal stiffness boundary conditions," Geomechanics and Geophysics for Geo-Energy and Geo-Resources, vol. 7, p. 35, 2021.

[26] Q. Wang, Z. Jiang, B. Jiang, H. Gao, Y. Huang, and P. Zhang, "Research on an automatic roadway formation method in deep mining areas by roof cutting with high-strength boltgrouting," International Journal of Rock Mechanics and Mining Sciences, vol. 128, Article ID 104264, 2020. 